\title{
Massive pericardial effusion resulted from hypothyroidism: a case report
}

\begin{abstract}
Hypothyroidism is an endocrine disorder characterized by high level of thyroid stimulating hormone and normal or low level of free thyroxine 4 (FT4). Mild pericardial effusion may complicate hypothyroidism but massive pericardial effusion or cardiac tamponade is quite uncommon. A 40 year old female presented to our emergency unit complaining of worsening shortness of breath for one week, transthoracic echocardiography revealed massive pericardial effusion. Laboratory examination showed elevated thyroid stimulating hormone (TSH), and decreased thyroxine (T4) and triiodothyronine (T3) levels. The patient diagnosed as a case of primary hypothyroidism complicated by pericardial effusion and treated with L-thyroxine replacement therapy. Possibility of hypothyroidism should be put in mind when assessing cases of pericardial effusion, even if there were no overt features of the disease, especially when other commoner causes of pericardial effusion were excluded.
\end{abstract}

Keywords: hypothyroidism, massive pericardial effusion
Volume I4 Issue 6 - 202I

\author{
Sufian Khalid M. Nor, ${ }^{1,2}$ Yousif Abdullah, ${ }^{2}$ \\ AbubakerTagelssir Taha Mohammed, ${ }^{2}$ \\ Mohamed H.Ahmed, ${ }^{3}$ Sarra O Bushara,' \\ Mosab Nouraldein Mohammed Hamad, ${ }^{4}$ \\ Samaher Mozamil Mohamed Abdelrahim, ${ }^{2}$ \\ Remaz Khalid Hassan Ahmed, ${ }^{2}$ Almoatasim \\ Mohamed Aabdelmagid Elnaema, ${ }^{2}$ \\ Mohammed Adil Yassen Ali ${ }^{2}$ \\ 'Department of Medicine, Faculty of Medicine, Nile Valley \\ University, Sudan \\ ${ }^{2}$ Alshap Teaching Hospital, Sudan \\ ${ }^{3}$ Department of Medicine, Milton keynes University Hospital \\ NHS, UK \\ ${ }^{4}$ Faculty of Health Science, Elsheikh Abdallah Elbadri University, \\ Berber, Sudan
}

\begin{abstract}
Correspondence: Mosab Nouraldein Mohammed Hamad, Phylum of Medical Parasitology, Department of Medical Laboratory Sciences, Faculty of Health Science, Elsheikh Abdallah Elbadri University, Berber, Sudan, Emailmusab.noor13@gmail.com
\end{abstract}

Received: June 20,202I | Published: November 25, 202 I

\section{Introduction}

Hypothyroidism is a common endocrine disorder resulting from deficiency of thyroid hormones. The clinical manifestations of hypothyroidism may vary depending on the age of the patient at the time of diagnosis and the severity of hormone deficiency. The most commonly reported symptoms of hypothyroidism are weight gain, constipation, cold sensitivity, fatigue, and dry skin..$^{1-3}$ Less common signs include myopathy, carpal tunnel syndrome, and hoarseness of voice. Thyroid hormone deficiency can affect almost any organ system. Profound cardiovascular system effects can occur; one of theserious complications of hypothyroidism is pericardial effusion. ${ }^{4}$

Pericardial effusion is a known complication of hypothyroidism with the incidence ranging from 3-6\% in mild cases of hypothyroidism to $30 \%-80 \%$ in severe hypothyroidism..$^{5}$ Cardiac tamponade may occur. Hypothyroidism causes pericardial effusion through increased permeability of the epicardial vessels and decreased lymphatic drainage of albumin, resulting in accumulation of fluid in the pericardial space. The majority of effusions are asymptomatic due to slow fluid accumulation. In this report we presented a patient who presented with massive pericardial effusion caused by primary hypothyroidism.

\section{Clinical scenario}

A 40year old female presented to the emergency unit at Atabra teaching hospital river nilestate, Sudan. Complaining of exertionaldysponea and lower limb swelling for one week. She has no orthopnea, paroxysmal nocturnal dysponea, chest pain or cough. The patient also reported symptoms of hypothyroidism for the last month in form of weight gain despite decreased appetite, fatigue, hair loss, muscle and joint pain and irregular cycle. She was not known to have any chronic illnesses before. On examination patient was ill, clinically anemic, PR881min RR20lmin and BP 110/80. There were features of hypothyroidism in the form of per orbital edema, muffled heart sound with normal respiratory sound. No murmur, gallop rhythm orengorgement of the jugular veins. Chest X-ray (Figure 1) showed increased cardiothoracic ratio. Ejection fraction at echocardiography was $66 \%$, due to detection of pericardial fluid levels of 2.2 anteriorly and 3-4 posteriorly, a diagnosis of massive pericardial effusion was made.

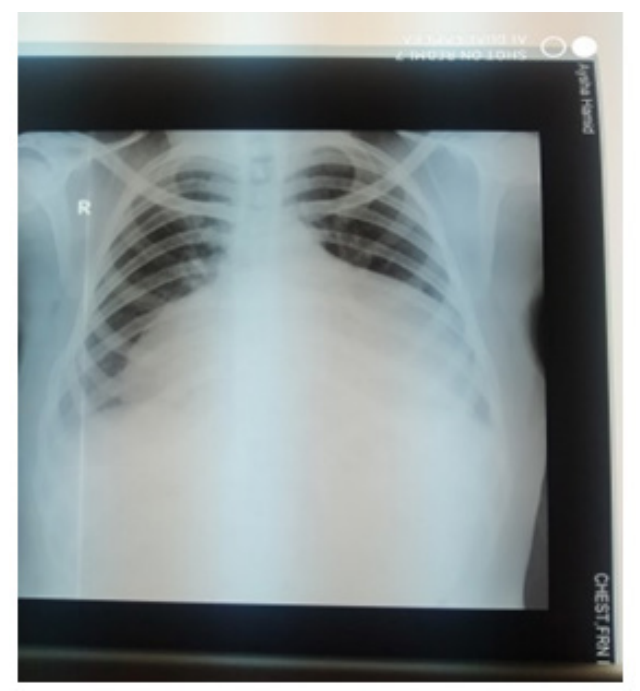

Figure I Chest X-ray showed increased cardiothoracic ratio. 
Abdominal and pelvic ultrasound was normal. Complete blood count show hemoglobin $3.8 \mathrm{~g} / \mathrm{dl}$ microcytic hypochromic, (MCV 71.7 $\mathrm{fl}, \mathrm{MCH} 16.4 \mathrm{pg}, \mathrm{MCHC} 23.1 \mathrm{~g} / \mathrm{dl}$ ) accordingly patient received 3units of blood. Erythrocyte sedimentation rate, electrolytes, renal and liver function tests were normal, regarding thyroid function test TSH was more than $110 \mathrm{uIU} / \mathrm{ml}$ (Normal range 0.4 _ 4.3), T3 $0.26 \mathrm{ng} / \mathrm{ml}$ (Normal range $0.79 \_1.58$ ) and T4 0.2ug/dl (Normal range $4.9 \_11$ ), lipid profile revealed high cholesterol, So the patient was diagnosed as a case of primary hypothyroidism complicated by massive pericardial effusion, anemia, and hyperlipidemia. $100 \mathrm{mcg}$ L-thyroxine therapy and $20 \mathrm{mg}$ atorvastatin were initiated. The patient showed clinical improvement and discharged in a good condition.

After one month TFT was done again and it was normal, TSH $0.47 \mathrm{mIU} / \mathrm{L}$ (normal rage $0.38-4.3$ ) T4 was $6.1 \mathrm{nmol} / \mathrm{L}$ (normal rage 4.9-11) T3 was $0.78 \mathrm{nmol} / \mathrm{L}$ (normal rage $0.79-1.58$ ) and chest $\mathrm{X}$-Ray (Figure 2) was normal. The patient continued to be followed up monthly, and showed a good outcome.

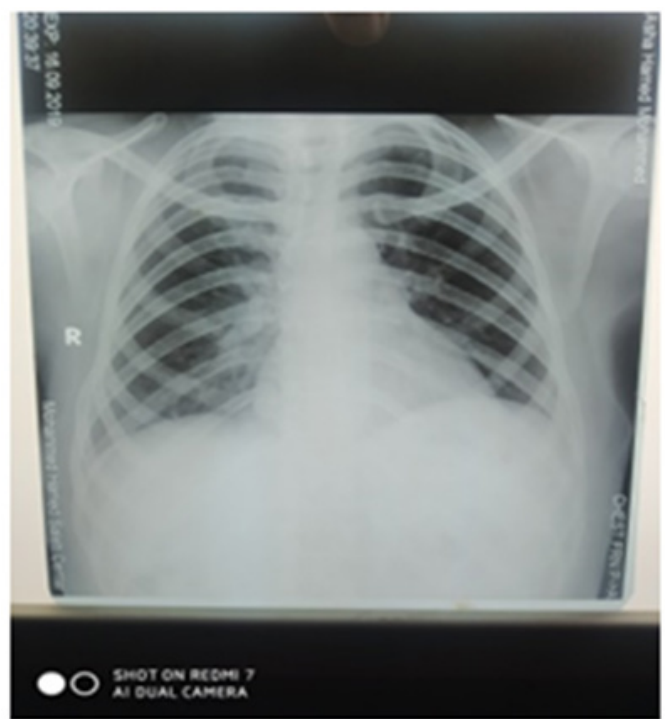

Figure 2 Chest X-ray Normal.

\section{Discussion}

Hypothyroidism, an endocrine disorder that occur as a result of low or absent functional thyroid hormone, and is diagnosed when decreased levels of thyroid hormones cause an increased secretion of thyroid-stimulating hormone (TSH). ${ }^{6}$

Hypothyroidism is associated with many cardiovascular manifestations including dyspnea, bradycardia, exercise intolerance, diastolic hypertension, cardiomegaly, muffled heart sounds, and also pitting or non-pitting edema can be seen on the physical examination. ${ }^{7,8}$ The relation between hypothyroidism and pericardial effusion and other effusions is well established. ${ }^{9}$ Hypothyroidism causes increased permeability of the pericardial capillaries to albumin. This, in addition to decreased drainage of albumin into the lymphatic system, leads to increased colloid pressure within the pericardium and hence, decreased colloid osmotic pressure gradient between the pericardial space and pericardium. This culminates in the accumulation of fluid in the pericardial space. ${ }^{10-13}$

Normally the pericardium contains 10 to $15 \mathrm{ml}$ of fluid as a result of plasma ultrafiltration, but as mentioned hypothyroidism causes an increase in the fluid of the pericardium, even without obvious signs and symptoms. ${ }^{14}$
Cardiac tamponade is a very rare complication of hypothyroidism because of the slow rate of accumulation of pericardial fluid and the elasticity of the pericardium. ${ }^{15}$ Pericardial effusion typically resolves as thyroid levels are normalized and therefore rarely requires intervention beyond hormone replacement. Generally pericardial effusion slowly disappears after obtaining an euthyroid status following several months of treatment, preventing unnecessary pericardiocentesis in these patients. ${ }^{16}$

If cardiac tamponade occurs it is an indication of emergency pericardiocentesis. ${ }^{17,18}$ In our patient, clinical signs of tamponadesuch as pulsusparadoxus or jugular-venous distension-were absent and she was haemodynamically stable. So decision to treat her with thyroid hormone replacement was made together with close observation and assessment, the patient had a good response to thyroxine.

\section{Conclusion}

Hypothyroidism can have different scenarios at presentation and sometimes may be asymptomatic or subclinical or present with a complication like pericardial effusion. The possibility of hypothyroidism should be thought of in every patient who present with unexplained pericardial effusion even with no overt signs or symptoms. The treatment is simple and the resolution of pericardial effusion is satisfied after initiation of thyroxine replacement therapy.

\section{Acknowledgments}

None.

\section{Conflicts of interest}

Author declares there are no conflicts of interest.

\section{Funding}

There was no funding for this report.

\section{References}

1. Carlé A, Pedersen IB, Knudsen N, et al. Hypothyroid symptoms and the likelihood of overt thyroid failure: a population-based case-control study. Eur J Endocrinol. 2014;171(5):593-602.

2. Diaz A, Lipman Diaz EG. Hypothyroidism. Pediatr Rev. 2014;35(8):336347.

3. Samuels MH. Psychiatric and cognitive manifestations of hypothyroidism. Curr Opin Endocrinol Diabetes Obes. 2014;21(5):377-383.

4. Chahine J, Ala CK, Gentry JL, et al. Pericardial diseases in patients with hypothyroidism. Heart. 2019;105(13):1027-1033.

5. Dattilo G, Crosca S, Tavella S, et al. Pericardial effusion associated with subclinical hypothyroidism. Int J Cardiol. 2011;153(3):e47-e50.

6. Udovcic M, Pena RH, Patham B, et al. Hypothyroidism and the heart. Methodist Debakey Cardiovasc J. 2017;13(2):55-59.

7. Bajaj R, Mehrzad R, Singh K, Gupta JP. Cardiac tamponade in hypothyroidism. Case Reports. 2014;2014:bcr2014204076.

8. Wiersinga WM. Hypothyroidism and myxedema coma. In: De Groot LJ, Jameson JL, Editors. Endocrinology Adult and Pediatric. 6th edn. Philadelphia: Saunders; 2010.

9. Gottehrer A, Roa J, Stanford GG, et al. Hypothyroidism and pleural effusions. Chest. 1990;98(5):1130-1132.

10. Vogiatzidis K, Zarogiannis SG, Aidonidis I, et al. Physiology of pericardial fluid production and drainage. Front Physiol. 2015;6:62. 
11. Yamanaka S, Kumon Y, Matsumura Y, et al. Linkbetween pericardial effusion and attenuation of QRS voltage in patients with ypothyroidism. Cardiology. 2010;116(1):32-36.

12. Parving HH, Hansen JM, Nielsen SL, et al. Mechanisms of edema formation in myxedema-increased protein extravasation and relatively slow lymphatic drainage. N Engl J Med. 1979;301(9):460-465.

13. Stewart RH, Rohn DA, Allen SJ, et al. Basic determinants of epicardial transudation. Am J Physiol. 1997;273(3):H1408-H1414.

14. Sachdev Y, Hall R. Effusions into body cavities in hypothyroidism. The Lancet. 1975;305(7906):564-566.

15. Butala A, Chaudhari S, Sacerdote A. Cardiac tamponade as a presenting manifestation of severe hypothyroidism. BMJ Case Rep. 2013;2013:bcr2012005281
16. Omura Y, Ugi S, Sugimoto T, et al. Massive pericardial effusion secondary to Hashimoto's disease. European Journal of Internal Medicine. 2007;18(5):438-440.

17. Smolar EN, Rubin JE, Avramides AV, et al. Cardiac tamponade in primary myxedema and review of the literature. Am J Med Sci. 1976;272(3):345352 .

18. Hardisty CA, Naik DR, Munro DS. Pericardial effusion in hypothyroidism. Clin Endocrinol (Oxf). 1980;13(4):349-354.

19. Omura Y, Ugi S, Sugimoto T, et al. Massive pericardial effusion secondary to Hashimoto's disease. European Journal of InternalMedicine. 2007; 18(5):438-440. 